NBER WORKING PAPERS SERIES

RATIONAL FINITE BUBBLES

Franklin Allen

Gary Gorton

Working Paper No. 3707

\author{
NATIONAL BUREAU OF ECONOMIC RESEARCH \\ 1050 Massachusetts Avenue \\ Cambridge, MA 02138 \\ May 1991
}

This paper is part of NBER's research program in Financial

Markets and Monetary Economics. Any opinions expressed are those of the authors and not those of the National Bureau of Economic 
NBER Working Paper \#3707

MaY 1991

\title{
RATIONAL FINITE BUBBLES
}

\begin{abstract}
There has been a long-running debate about whether stock market prices are determined by fundamentals. To date no consensus has been reached. An important issue in this debate concerns the circumstances in which deviations from fundamentals are consistent with rational behavior. A continuous-time example where there are a finite number of rational traders with finite wealth is presented. It is shown that a finitely-lived security can trade above its fundamental.
\end{abstract}

Franklin Allen

The Wharton School

University of Pennsylvania

Philadelphia, PA 19104
Gary Gorton

The wharton School

University of

Pennsylvania

Philadelphia, PA 19104 NBER and 


\section{Introduction}

There has been a long and continuing debate on the determinants of stock prices. One view is that these prices reflect economic fundamentals; that is, a firm's stock price equals the present discounted value of its dividends. Another view is that stock prices are "bubbles" and deviate from their fundamentals. As an empirical matter, there is currently no consensus on which of these views is correct.

Ilistorically, the possibility that stock prices are "bubbles" was raised by a number of extreme incidents. Perhaps the most well-known of these is the South Sea Bubble. During the first six months of 1720 the stock price of the British South Sea Company rose by 642 percent; during the last six months of 1720 the price fell back to its original value. A similar rise and sudden decline occurred in the stock price of John Law's Mississippi Land Company in France. Both episodes were reminiscent of the Dutch Tulip Mania in the previous century, and were precursors of the stock market crashes of subsequent centuries of which October 1929 and October 1987 are perhaps the most famous. While it is by no means clear that these events constitute evidence of "bubbles" (see e.g. Garber (1989)), they were important in that many of them lead to regulation. For example, the South Sea Bubble caused the British Parliament to pass the South Sea Act which effectively eliminated the stock market as a source of funds for over a century. In the United States, the Great Crash of 1929 lead to the creation of the SEC and the introduction of numerous regulations, many of which are still in force.

More recently, the results of Leroy and Porter (1981), Shiller (1981), and Grossman and Shiller (1981), among others, suggest that stock prices deviate from market fundamentals. There is again no wide agreement on the validity of these studies; those who have challenged the methodology adopted include Flavin (1983), Kleidon (1986a,b) and Marsh and Merton (1986). West (1988) provides a more complete survey of this and related controversies. Price 
paths that deviate from fundamentals lave also been observed in experimental settings (see Smith, Suchanek and Williams (1988)).

In addition to the empirical debate about the determinants of stock prices, a growing theoretical literature has begun to address the question of how asset prices can deviate from market fundamentals. Camerer (1989) gives a full survey of this literaturc. In infinite horizon models, rational bubbles have appeared as explanations for the existence of fiat money starting with Samuelson (1958). Important contributions were subsequently made by Wallace (1980), Flood and Garber (1980), Blanchard (1979), Blanchard and Watson (1982) and Tirole (1985), among others. Although these theories can explain a number of features of "bubbles" they are not entirely satisfactory explanations of the phenomena the empirical literature on stock prices has been concerned with. Some of these models require that prices grow slower than the expected growth rate of the aggregate wealth of the economy. There is no explanation of how bubbles get started or of why they crash since starting and stopping are taken as exogenous in these types of models. Diba and Grossman (1988) have argued there is no possibility that price bubbles can crash and restart. Also these theories cannot address the question of whether finitely-lived security prices can deviate from fundamentals.

The major result for finite horizon models is a negative one. Tirole (1982) argues that in a discrete time finite horizon setting stock prices cannot deviate from fundamentals unless traders are irrational or myopic. He makes three important assumptions in ruling out finite bubbles. First, he points out that with a finite horizon and a finite price path the bubble would never get started because it would "unravel." To see this let the final date in the economy be $T$. Then at date $T-1$ an agent would not buy the asset at a price above the discounted value of its payoff at $T$ because he would incur a loss if he did so. Therefore, the bubble cannot exist at $T-1$. Similarly, by backward induction it follows that a bubble cannot exist at any point in time. Sccondly, with a finite horizon traders cannot be induced to hold the stock by a price path that goes to infinity because there is finite wealth. Consequently, 
there must be a date at which the (real) price path necessary to support the bubble exceeds the total available wealth in the economy. At that date the bubble will crash, but then at the date before that no other trader will buy the asset. Again by backward induction the bubble cannot get started. Finally, without insurance motives for trading not all of the finite number of traders can rationally expect to benefit since they know that the bubble is a zero-sum game. If traders are risk averse, some must be strictly worse of since they bear risk and not everybody can have a positive expected return.

Tirole's (1982) results exemplify the difficulties of constructing theories which are based on conventional assumptions and which are consistent with bubbles. These difficulties have lead some authors to abandon the traditional neoclassical assumption of rational behavior. One example is Shiller (1984) who models stock prices as being subject to "fads." Another is DeLong, Shleifer, Summers, and Waldmann (1990) who assume that some traders continue to hold beliefs even after it becomes clear these are rejected by the data. These irrational traders are consistently overly optimistic (or overly pessimistic) and take larger positions than they would do if they were rational. This means they bear more risk than is optimal but their wealth is not driven to zero. They therefore persistently cause stock prices to deviate from their fundamental. (See Camerer (1989) for other examples.)

The model presented below takes a different approach. We assume all agents are rational but they populate an imperfect world which is characterized by asymmetric information. In particular, there is an agency problem between investors and portfolio managers which is similar to that originally identified by Jensen and Meckling (1976) between bondholders and equityholders. In the corporate finance literature the analysis of agency relationships is now commonplace and their implications for firms' investment decisions are well known. It is widely accepted that asymmetric information can lead to firms making inefficient investment decisions. Despite the fact that in the United States and many other countries, a majority of the wealth held in stocks is invested indirectly through financial intermediaries, the implica- 
tions of agency relationships between investors and portfolio managers for asset pricing have not been fully investigated. It is argued below that one of the manifestations of asymmetric information in this context is that asset prices can deviate from their fundamental values and be subject to bubbles.

We assume there are two types of people that can obtain the qualifications necessary to become a portfolio manager. The first group, who are good portfolio managers, can each identify a number of undervalued firms and this allows them to make a higher return on the funds they invest than traders with no special information. We use a version of the Glosten and Milgrom (1985) model to show how they accomplish this. Thus markets are not strong-form efficient but this is not inconsistent with rationality. The second group consists of bad portfolio managers who are unable to identify undervalued firms. Lenders cannot observe which type of portfolio manager they are entrusting their wealth to.

In Section 2 we focus on the actions of the bad portfolio managers. We assume that these portfolio managers, who have no wealth of their own, receive a proportion of the profits that they make so their payoff has the form of a call option; this is later shown to be an optimal contract. This type of compensation scheme, where the payment to the portfolio manager is a call option on the portfolio's incremental return, is widely used in practice in the investments industry (sce, e.g., Kritzman (1987)). In our model its important feature is that it can induce risk-loving behavior.

We show that the trading activity of these portfolio managers causes a bubble in the sense used by Harrison and Kreps (1978), and Tirole (1982). A bubble is defined to be a price path supported by the trading of agents who are "willing to pay more for [the security] than they would pay if obliged to hold it [to the horizon]." We show that the bad portfolio managers strictly prefer to speculate in this sense. This strict preference can occur because of the fact that there is an asymmetry in their incentives. If they lose the money entrusted to them they obtain nothing no matter how badly they do. If they do well they keep a 
proportion of what they make. They are therefore prepared to purcliase securities which are trading above their fundamental provided there is some chance of a capital gain even though they know that there is a good chance they will lose their investors' money when the bubble crashes.

In Section 3 we consider the entire stock market, of which the bad portfolio managers are a part. In Section 3.1 we develop a model of how the good portfolio managers profitably trade on their information. In Section 3.2 we consider both groups of portfolio managers and demonstrate that the contract assumed in Section 2 is an optimal contract. It is not worthwhile for lenders to entrust their wealth to portfolio managers they are sure will speculate. However, they cannot tell them apart from the good portfolio managers that can identify undervalued firms. Therefore, in equilibrium, the good managers subsidize the ones that speculate and lenders earn their opportunity cost.

The example presented in Sections 2 and 3 shows that bubbles can occur in finite horizon models when traders are rational. Since our results differ from those of Tirole an important issue concerns the robustness of our example and its implications for theories of asset pricing. Section 4 discusses the critical elements of the example that lead to bubbles.

\section{Speculative bubbles}

This section considers a stylized model of a stock market in which there are three traders. We assume that these traders have no wealth of their own but instead manage other people's wealth for them. They receive a proportion of any profits they make. Below it is shown that this contract can be optimal. Subsection 2.1 outlines the basic model. The key issue is whether or not these traders perceive there to be some chance of a capital gain at all points in time. This depends on what they conjecture about the strategies of other traders. We consider a very stylized structure which makes traders' conjectures about other traders' actions very simple. In particular, we assume in subsection 2.2 that traders leave the market 
when they "die" and that their "death" times are correlated in a particular way. This rationale for exiting from the market, and the correlation structure of these "death times," are clearly not meant to be taken literally but rather are devices for streamlining the model in order to focus on the theoretical issue of the existence of bubbles in a finite world. The main point is to develop a simple structure under which the logical sequence of conjectures traders go through will not lead to unraveling but to rational traders deciding to speculate. Having developed this structure we go on to briefly show, in subsection 2.3 , how the model can be extended to the case where a trader's exil from the market arises from an endogenous decision rather than being due to an exogenous event.

\subsection{The basic model}

The following assumptions detail the basic model.

(A1) There are three traders called Persons 1, 2 and 3.

(A2) The model lasts for one continuous period, beginning at $t=0$ and ending at $t=1$. Trades can occur at any time between 0 and 1 .

(A3) The traders consume just before they die which occurs somewhere between 0 and 1 .

(A4) The agents' utility is an increasing function of consumption. They can be either risk neutral or risk averse.

(A5) Person 1 dies at date $t_{1}$ which is drawn from a uniform distribution on $[0,1)$. Person 2 dies at $\ell_{2}$ where

$$
t_{2}=t_{1}+\frac{1}{3}\left(1-t_{1}\right)
$$

Person 3 dics at $t_{3}$ where

$$
t_{3}=t_{1}+\frac{2}{3}\left(1-t_{1}\right)
$$


(A6) Agents learn their death times just in time to allow them to trade and consume before they die. Death is private information.

(A7) There exists a firm with a certain payoff which for simplicity we normalize to zero. In other words the fundamental is zero. This is known to all traders. The firm issues one indivisible share. This share cannot be short sold.

(A8) Person 1 is always endowed with the share. Person 1 knows his identity.

(A9) Persons 2 and 3 are not endowed with any shares. They do not know their identities (i.e., whether they are going to die last) and assign equal weight to each of the two possibilities.

(A10) Persons 2 and 3 have no wealth of their own. However, they are able to invest other people's wealth. They are to be thought of as portfolio managers. They have a fixed amount $B(=1$ in illustrations) they invest. The amount $\pi$ they repay to investors if the amount they have at the end is $y$, is:

$$
\begin{aligned}
\pi & =B+\alpha(y-B) & & \text { for } y \geq B \\
& =y & & \text { for } y<B
\end{aligned}
$$

where $0 \leq \alpha \leq 1$. (In illustrations it is assumed that $\alpha=0.95$.) In effect, the payoff the portfolio managers receive is a call option.

The accounting system is such that they cannot simply consume the money they borrow. They can only consume the fee that they are paid for managing the portfolio. It follows from (3) that this is a proportion $1-\alpha$ of the profits that they make if these are positive and nothing if they are negative.

(A11) The identity of the owner of the share is private information throughout.

(A12) Trade occurs in the following way. All traders have the same expectations about prices $p(t)^{e}$ at which trades will occur at time $t$. When a person decides to sell the 
share he seeks out a buyer. He locates one or the other of the traders that remain in the market with equal probability. If he finds another trader then trade occurs at $p(t)^{e}$. If the seller cannot find a buyer this becomes public information and the price of the share falls to zero. In illustrations it is assumed that

$$
p(t)^{e}=t \quad \text { for } t \in[0,1)
$$

(A13) When a trade occurs only parties to the trade observe the transaction.

(A14) All agents know the structure of the model and the distributions of the random variables, but do not observe the particular realisations of random variables.

\subsection{Example of a bubble}

The share considered has a fundamental of zero. It is clear that an equilibrium with $p(t)^{e}=0$ exists where the share price reflects this fundamental. The question that we address is the following. Do there exist other price paths such that a rational agent is prepared to buy the share at a strictly positive price even though he knows the final payoff to the share is zero? The agency problem between investors and their portfolio managers is not sufficient by itself to provide a satisfactory theory of bubbles in asset prices. When the portfolio managers have a call option on the incremental value of the portfolio, they may be indifferent between buying and not buying a stock that is trading above its fundamental. If they are prepared to buy then bubbles may exist. However, a theory which critically depends on people's behavior when they are indifferent is not very satisfactory. We therefore develop a theory where portfolio managers in the group that cannot identify undervalued securitics are strictly better off investing in stocks trading above their fundamental.

Our first result is:

Proposition 1 When death times are unknown there exists a set of self-fulfilling beliefs such that two trades will always occur at a strictly positive price between date 0 and date 1 
provided:

(i) $0<p(t)^{e}<B$ for all $t \in[0,1)$;

(ii) $p^{\prime}(t)^{e}>0$ for all $t \in[0,1)$.

To see why this holds consider a numerical example where $t_{1}=0.1$ so that $t_{2}=0.4$ and $t_{3}=0.7$ (from (1) and (2)). As mentioned in the previous subsection we also assume $p(t)^{e}=t, B=1$ and $\alpha=0.95$. For ease of exposition we start by describing a sequence of events, shown in Figure 1, without analyzing the traders' decisions. We then consider a set of beliefs and show that these support the decisions in Figure 1. Finally, we show that the beliefs are self-fulfilling.

At $t=0$ Person 1 is endowed with the share. At $t=0.1$ he finds out he's going to die and searches for a buyer which is Person 2 or 3 with probability 0.5 . For concreteness we assume he finds Person 2 who buys the share at a price of 0.1 . At $\iota=0.4$, just before he dies, Person 2 searches for a buyer and finds Person 3 who buys the share at a price of 0.4. He makes a profit of $0.4-0.1=0.3$ and after repaying his investors consumes $(0.05)(0.3)=0.015$. At $t=0.6$ Person 3 searches for a buycr, but finds none. The bubble bursts and the price of the stock falls from 0.6 to zero. Finally, at $\ell=0.7$ Person 3 dies. At the time of his death, he has 0.6 remaining and so is only able to return this amount to his investors. He consumes nothing.

Consider the following set of beliefs. Given that $p^{\prime}(t)^{e}>0$, all agents believe that:

(a) if there is a prospective buycr alive he will be prepared to buy the share when approached.

Agents who do not know their own identity believe that:

(b) any agent offering to sell at a date in the interval $0 \leq t<1 / 3$ is Person 1 selling at $t_{1}$ with probability 1 ; and 
(c) any agent offering to sell at a date in the interval $1 / 3 \leq t<1$ is Person 1 selling at $t_{1}$ with probability 0.4 or Person 2 or 3 selling at $t_{2}$ with probability 0.6 .

We demonstrate below that these beliefs support the sequence of actions in Figure 1 as an equilibrium and that they are self- fulfilling. Figure 2 outlines the sequence of the buyers' conjectures about the seller's identity discussed below.

First consider Person 1's decision. He knows from the structure of the model that for $0 \leq t \leq \imath_{1}$ Persons 2 and 3 will be alive. Thus from (a), Person 1 believes he can sell the share at any time until his death. Since the share price is increasing through time, it is optimal for Person 1 to hold the share until he has to sell it at his death time $t_{1}$. Thus at $t=0.1$, Person 1 will search for a buyer. There is a 0.5 probability he will find Person 2 and a 0.5 probability he will find Person 3. For concreteness we suppose that Person 2 is found.

Next consider Person 2's decision. From (b), he believes that the seller is Person 1. He can put himself in the place of Person 1 and by doing so deduce that Person l's optimal strategy is to sell at his death time. He therefore knows that $t_{1}=0.1$ which implies that $t_{2}=0.4$. This means that he should not wait past $t=0.4$ to sell the share since if he survives that date he will be the sole remaining trader; until that date there will definitely be another buyer. Since the price is increasing, he should sell at $t=0.4$.

Person 2 finds the remaining trader, Person 3, at $t=0.4$. Consider Person 3's decision. Since he was not endowed with the share he knows he is Person 2 or 3 , but does not know which. Since he is approached at $t=0.4$ he does not know whether the seller is Person 1, 2, or 3. It follows from (c) that he believes there are two possibilities. There is a 0.4 probability that the seller is Person 1 in which case $t_{1}=0.4$. This implies that $t_{2}=0.6$ in which case from (c) the share could be sold at any date up to this point. We refer to this first possibility as state $S$ to indicate the share can be sold again. Ile also believes there is a 0.6 probability that the seller is Person 2 or 3 . In this case Person 1 must have sold it at $t_{1}=0.1$ and there will be no one for the trader to resell it to. We refer to this second possibility as state $N$ to 
indicate that no resale is possible.

The payment schedule in (3) implies Person 3 cannot lose from buying the share and he can gain if he manages to resell it at a higher price. Since he attaches a 0.4 probability to there being another trader who he can resell the share to at a higher price, he is strictly better off purchasing the share. What is the optimal time for him to try to sell the share? If state $N$ is the true state, then there is no other trader to sell the share to. This possibility therefore has no effect on his optimal selling time. If state $S$ is the true state, then $t_{1}=0.4$ and $t_{2}=0.6$. Hence, since price is rising his optimal action is to search for a buyer at $t=0.6$. In fact, in this example there is no other buyer to be found, so at $t=0.6$ he realises that he is Person 3 and the bubble crashes. At $t=0.7$ Person 3 dies.

So far we have considered the case where $t_{1}=0.1$. It can be seen that for $0 \leq t_{1} \leq 1 / 3$ the analysis is the same because only Person 1 can die in this interval. For $1 / 3 \leq t_{1} \leq 1$ it can be seen that the beliefs (a) again make it optimal for Person 1 to sell at his death time. The difference here is that the identity of the seller in the first transaction will be unknown. The buyer's decision is then the same as Person 3's at $t=0.4$ above; he cannot distinguish between states $S$ and $N$ and assigns probabilities of 0.4 and 0.6 to these, respectively. Any other transactions in the interval $1 / 3 \leq t \leq 1$ also have this feature so that the analysis of other possible cases is similar to that of the illustration.

Why are the beliefs (a), that when found a prospective buyer will always purchase the share, correct in equilibrium? First, consider somebody who is approached after $t=1 / 3$. A prospective purchaser will be better of buying provided he believes that there is some probability that he can resell the share. This depends on whether there is some probability he can locate a prospective buyer and this conjectured buyer believes that he can resell the share, and so on. From the point of view of any new buyer there is always a 0.4 probability of another willing buyer later. This chance of state $S$ is independent of time. At any point a prospective buyer cannot distinguish between the seller being Person 1 or the seller being 
Person 2 or 3 and hence whether or not another buyer remains. As a buyer goes through the logical sequence of conjectures concerning whether he will be able to resell, he knows for certain that the share cannot be resold more than once. However, the person that he might sell to will think there is a 0.4 probability he will be able to resell and so on; as far as each buyer in the sequence is concerned there is always a possibility that the share can be resold once. This is true for an infinite sequence of conjectured buyers. No matter how close to $t=1$ a sale were to occur, (1) and (2) together with $p^{\prime}(t)^{e}>0$ imply that there is always a 0.4 possibility of reselling the share at a profit so unravelling does not occur. For anybody approached before $t=1 / 3$ the analysis is similar except there is a probability of 1 they can locate another willing buyer. Thus beliefs (a) are correct in equilibrium.

Why are beliefs (b) and (c) correct in equilibrium? It was argued above that Person 1 always sells at his death time $t_{1}$ and the person he sells to always sells at $t_{2}$. The unconditional distribution of $t_{1}$ is uniform on $[0,1)$ with density 1 and the unconditional distribution of $t_{2}$ implied by $(1)$ is uniform on $[1 / 3,1)$ with density $3 / 2$ as shown in Figure 3 . Hence, the beliefs (b) that for $0 \leq t_{1} \leq 1 / 3$, anybody selling the stock is Person 1 with probability 1 are correct. For $1 / 3 \leq t_{1} \leq 1$ the probability the seller is Person 1 (i.e. state $S$ ) is $1 /(1+3 / 2)=0.4$ and the probability the seller is Persons 2 or 3 (i.e. state $N$ ) is $(3 / 2) /(1+3 / 2)=0.6$. Beliefs (c) are, therefore, also correct in equilibrium.

These arguments show that provided the expected price is always below $B$ so that traders have cnough resources to buy the share and provided the price path is rising, there will always be two trades at a strictly positive price. Thus Proposition 1 is demonstrated.

Why do our results differ from those of Tirole (1982)? His first argument is that in a discrete time finitc horizon model a bubble would never get started because it would unravel. If an asset's payof at date $T$ is known to be zero then at date $T-1$ nobody will buy it at a positive price. Similarly at datc $T-2$ and so on so that the asset is always worthless. In our model time is continuous so that although there is a final date $t=1$ there is no date 
corresponding to $T-1$; no matter how close to $t=1$ it is always possible to resell the share before the final date. The unravelling argument is not applicable.

Tirole's second argument is that with a finite horizon the price path cannot go to infinity becausc there is finite wealth. If the price path did go to infinity the amount needed to purchase the share would exceed the total wealth available in the economy. Again by backward induction the bubble cannot get started. In our model the price path does not go to infinity. The reason that this is not necessary to support the equilibrium is the correlation structure of death times. No matter how close to $t=1$ a trade occurs the probability of finding a subsequent buyer is 0.4 . It is always optimal for the trader to hold the stock until the conjectured $t_{2}$. Without some correlation structure of this type, the chance of finding a buycr would fall towards zero and the price path would need to rise to infinity to induce the trader not to sell.

IHis final argument for bubbles not existing is that, without insurance motives for trading, not all of the finite number of traders can expect to be better off ex ante since they know that the bubble is a zero-sum game. If they are risk averse some must be strictly worse off. In our model all the traders participating in the bubble are strictly better off ex ante. The reason is that they are investing with other people's money and their reward structure is such that they do not care about the magnitude of any losses they incur. The people who bear the losses expost are the investors lending them the money. They are willing to lend because the traders are pooled with portfolio managers that can identify profitable investment opportunities and they effectively subsidize these losses by paying a higher interest rate than they would have to in the absence of the bad portfolio managers. This aspect of the model is explained in Section 3. 


\subsection{Extensions}

The purpose of most of the assumptions used in the previous section is to simplify the analysis. For example, having Person 1 endowed with the share limits the number of cases that need to be considered. It would also be possible to have the share randomly endowed. In that case neither Persons 1, 2, or 3 knows their identity and the number of possible states of the world each agent must consider is significantly increased. However, the results do not change substantively.

The assumption that outlines the way in which trade occurs is an important one. Its role is essentially similar to that of the Walrasian auctioneer and price-taking in standard competitive models since it allows strategic aspects of traders' behavior to be ignored. Its purpose is again to simplify the nature of the conjectures that people make about what could have happened in the past.

The proposition indicates that any price path which is monotone increasing is an equilibrium. In addition the fundamental is of course also an equilibrium. This multiplicity of equilibria is similar to that which arises in infinite horizon overlapping generations models. As in these cases one way of describing which equilibrium occurs is to associate each equilibrium with the outcome of an exogenous random event or "sunspot."

The analysis above has the feature that agents' decisions to leave the market are exogenous. As discussed in the introduction, "death" is not meant to be taken literally but rather is meant to represent any event that causes the trader to leave the market. For example, death could correspond to the timing of liquidity needs. The decision to leave the market can be made endogenous, and the model correspondingly more realistic, by extending the basic model outlined above. In this subsection we sketch such an extension. Proofs are provided in Allen and Gorton (1988).

To endogenize the exit decision suppose that there is a possibility of bankruptcy in which case the security will pay off zero immediately. There is also assumed to be a level of wealth 
for each trader beyond which the inarginal utility of consumption is so low that the rate at which their wealth is increasing is insufficient to compensate them for the risk of the firm going bankrupt so they sell and leave the market. In other words, for trader $i$ :

$$
\begin{aligned}
u(C) & =C \quad \text { for } C<C_{i}^{*} \\
& =C_{i}^{*} \quad \text { for } C \geq C_{i}^{*} .
\end{aligned}
$$

For Person 1 the critical level of wealth $C_{\mathbf{i}}^{*}$ is drawn from a uniform distribution on $[0,0.05)$. For Person 2

$$
C_{2}^{*}=\beta\left(0.05-C_{1}^{*}\right)
$$

where $\beta$ is the unobservable realisation of a random variable distributed uniformly on $(0,0.5)$. For Person 3 it is also the case that

$$
C_{3}^{*}=B\left(0.05-C_{i}^{*}\right)
$$

Agents learn their $C_{i}^{*}$ at $t=0$. The realisations are private information.

Note that if $\beta$ were a constant, then knowledge of $C_{i}^{*}$ would be sufficient to prevent bubbles because all other agents' $C_{i}^{*}$ 's could be computed once some agent was approached to buy the security. An agent would then know how many other agents remained in the market and an unravelling argument would hold. But, bubbles can exist if we suppose that there is another source of uncertainty, such as $\beta$ which reflects uncertainty about how the death times are linked. Even though each agent knows his own $C_{i}^{*}$, the second source of uncertainty, $\beta$, does not allow agents to infer the ordering of $C_{i}^{*}$ 's and so the sequence of logical conjectures here is similar to the previous case. Because of the uncertainty induced by $\beta$, there is always a positive probability of another buyer. By specifying a set of beliefs corresponding to the probabilities induced by the distribution of death times given the distribution of $\beta$, it can be shown that bubbles exist. As before a buyer will be willing to buy because he rationally conjectures that all future buyers will also buy. (This is proven in Allen and Gorton (1988).)

It can readily be seen that for $C$ in the relevant range $0 \leq C \leq 0.05$ a trader will sell the share when his wealth reaches $C_{i}^{*}$. This is because the utility from holding the share 
(assuming he is not the last person) is increasing when wealth is below $C_{i}^{*}$ and decreasing when it is above. When trader i's wealth reaches $C_{i}^{*}$ the effect is the same as dying in terms of his behavior: he sells and leaves the market. The formal arguments are similar since the structure of the $C_{i}^{-1}$ s $(i=1,2,3)$ induces the same ordering of exits as was previously assumed by the structure of death times.

In the case sketched there is a dramatic change in traders' marginal utilities of consumption. In general this is not necessary. All that is required is that there is some critical consumption level such that the marginal utility of consumption is low enough that it is no longer worthwhile holding onto the security because there is a chance of bankruptcy. Hence, in principal, any standard utility function, $u(\cdot)$, with a declining marginal utility of consumption can be consistent with bubbles provided the marginal utility of consumption falls to a low enough level. The assumption concerning the possibility that the security will be retired ensures that it is strictly optimal for the agents to sell the stock when they reach their critical consumption level.

An important feature of the case with standard utility functions is that the correlated structure of death times that was assumed previously is no longer critical. In the case considered, Persons 2 and 3 have identical utility functions but this is not essential. The critical consumption levels determine the period of time the traders hold the share; the ordering of times at which the traders leave is determined by the order in which they receive the share. The main thing that is important is that traders cannot identify whether or not they are the last person who is prepared to buy the share; it must always be possible that the person selling the share is the one that was endowed with it so that one other person remains to sell it to. Provided they always attach a positive probability to being able to rescll they are strictly better off buying the share and bubbles can exist.

In the model analyzed in Section 2.1 and 2.2 it was possible for buyers, between $0 \leq t \leq$ $1 / 3$, to make money since they were sure there would be a seller. However, this feature is 
due to the particular form of equations (1) and (2). It can be seen that in the version of the model in this section, where (1) and (2) are replaced by (6) and (7), there is never any time period in which buyers can be certain they will be able to sell the stock. Hence, the only people willing to trade in the market will be portfolio managers whose payoft is effectively a call option.

\section{The entire stock market}

In the previous section we considered the three traders who trade the stock which experiences the bubble. The three pcople who trade this stock are strictly better of in expected utility terms from doing this compared to not doing anything, even when they are risk averse. Person 1 is endowed with the stock and is able to sell at a positive price. The traders who are not endowed with the stock, Persons 2 and 3, are also strictly better off. The reason for this is that the money they invest is not their own. They manage other people's money and keep a share of any of the profits they make. If they are unsuccessful they repay less than they were given to manage and are no worse off than if they had not managed people's wealth. This implies, of course, that the lenders cannot make money or break even by lending to these portfolio managers alone. Why then would anybody be willing to lend to them? In this scction we consider a more complete model of the stock market with asymmetric information, where it is optimal for people to lend to portfolio managers using the contract assumed in (A10).

In the complete model consumers who wish to invest at $t=1$ invest their money with portfolio managers. There are two types of portfolio managers. 'Good' portfolio managers can identify a limited amount of undervalued securities. 'Bad' portfolio managers have no superior information. We begin, in Section 3.1, by describing how the good portfolio managers can profit from their superior information. We develop a setting similar to that of the Glosten-Milgrom (1985) model. Then, in Section 3.2, we consider optimal contractual 
arrangements between the investing consumers, who cannot observe portfolio manager type, and the portfolio managers. We show that the optimal contract involves pooling. Thus, in equilibrium, the losses of the bad portfolio managers, who speculate in the bubble stock, are effectively subsidized by the good portfolio managers. Figure 4 portrays the component parts of the entire stock market.

In Section 2 the payoffs to the security were known with certainty by everybody and the appropriate definition of a bubble was clear; if the security traded above its fundamental (the present value of its payoffs) this was said to be a bubble. With asymmetric information the notion of a bubble must be modified since investors with different information sets can have different views on a stock's fundamental. In this case one appropriate definition of a bubble is when the security trades at a price which is greater than the fundamental that is the highest out of all investors' information sets. The notion of a bubble used in Section 2 is then a special case of this definition where everybody has the same information about a particular security.

There are two types of people who acquire the necessary qualifications to become a portfolio manager. There are good portfolio managers, denoted by the subscript $g$, who can identify securities which are undervalued. The amount of stock they can identify as being undervalued costs $B$. The second type of person that attains the qualifications necessary to become a portfolio manager cannot identify undervalued securities. They can only identify bubble securities, and find it optimal to speculate as described in Section 2. These managers are denoted by the subscript $s$. The lender cannot observe the type of the portfolio manager. In this case it may be possible for type $s$ portfolio managers to obtain funds to speculate with even though in a full information world they would not be able to do so.

There are assumed to be two types of stocks: (i) asymmetric information stocks; and (ii) symmetric information stocks. Good portfolio managers can profit from their superior information by trading asymmetric information stocks, as we explain below. Bad portfolio 
managers speculate in the symmetric information stocks and bubbles may exist in these.

We assume that all agents are risk neutral and also add the following assumptions to the basic model.

(A15) There is a group of risk neutral lenders who are prepared to lend as much as investment firms require provided that on average their expected return is equal to their opportunity cost, $\delta$, which for simplicity is taken to be zero.

(A16) Investment firms cannot credibly precommit to keep on employing bad managers once they have been identified as bad.

(A17) The investment firms operate in a competitive industry and so make zero expected profits.

(A18) For ease of exposition we assume that the bad portfolio managers can identify a bubble stock with the price path and distribution of returns considered in Section 2.2. They each have a probability of $1 / 3$ of being Persons 1,2 and 3 . This implies that the probability distribution of their final gross return $y$ (i.e., including the money they borrow initially), given that $B=1$, is distributed as illustrated by the solid line in Figure 5. Person 1 makes a profit which is uniformly distributed between 0 and 1 so their gross profit is uniformly distributed between 1 and 2. Person 2 and Person 3's profit depends on whether or not they are found by Pcrson 1 when he decides to sell the stock. If they are found they make a profit which is uniformly distributed between 0 and $1 / 3$ so that their gross return is uniformly distributed between 1 and $4 / 3$. If they are not found by Person 1 when he sells, they make a loss which is uniformly distributed between $1 / 3$ and 1 so their gross return is uniformly distributed between 0 and $2 / 3$.

(A19) The good portfolio managers can each identify undervalued securities which cost 
$B=1$ (but no more than this). A portfolio of these securities has a stochastic return $y$ which has the distribution shown by the dotted line in Figure 5.

(A20) The good portfolio managers represent a proportion $\gamma$ of the total and the portiolio managers who speculate represent a proportion $1-\gamma$ of those who manage portfolios.

(A21) It is not possible for a lender to observe whether the portfolio manager invests his money in a profitable investment or whether it is used for speculation. However, the final value of $y$ is observable and can be contracted upon.

(A22) The parameter values are such that the portfolio managers who cannot identify the undervalued stocks are better off speculating than investing in all securities.

(A23) As in Glosten and Milgrom (1985), there exists a number of uninformed traders who face immediate liquidity needs which they satisfy by selling their securities. There also exists a number of uninformed traders who desire to buy securities. We refer to these traders as liquidity sellers and liquidity buyers, respectively. Liquidity sellers needs are greater than the aggregate amount that good portfolio managers have available for investment.

\subsection{Profitable trading with superior information}

In this subsection we develop a model in which the good portfolio managers make profits by trading the asymmetric information stocks. These profits offset the losses made by the bad portfolio managers who may speculate in some of the symmetric information stocks, which we term "bubble" stocks. The reason that good portfolio managers can make a profit is that there are liquidity traders whose consumption needs are sufficiently urgent that they are forced to sell at a price below the expected value of the stock.

A common form of trading is one in which a markel institution posts bid and ask prices, but limits the quantity that may be traded at that price. Trade is sequential. Over time 
both traders with superior information, and uninformed traders, buy and sell at these prices. As they transact, both the bid and the ask prices are adjusted upwards or downwards to reflect the information conveyed by the trades. This idea is elegantly modeled by Glosten and Milgrom (1985). In their model the market institution faces adverse selection and a zero profit condition. The market institution conditions the posted bid and ask prices on the event of a trade, so the prices are "regret froe." The informed traders make money; the liquidity traders lose a corresponding amount. We use a version of this model for asymmetric information stocks.

In this setting we can prove the following proposition:

Proposition 2 The initially posted bid and ask prices are lower than the unconditional expecied security values so that uninformed buyers break even; liquidily sellers reccive less than the unconditional expected value of their securities; and good portfolio managers have positive expected profits conditional on their information.

To see this, start by considering (A23). According to this assumption liquidity traders need to sell their shares immediately. In order to do this uninformed liquidity buyers must participale because the good portfolio managers (who are informed) do not have sufficient funds to satisfy the sellers' needs. Thus, the initially posted prices cannot be above the unconditional expected values of the shares, since the uninformed traders would be unwilling to buy at such prices.

Next, suppose prices were equal to the unconditional expected values of the shares. At such prices, the good portfolio managers will select stocks which are undervalued. The good stocks will have larger orders than bad stocks. Bad portfolio managers, and other uninformed agents, have an incentive to submit orders for the market portfolio. This is because they are risk neutral and have no information. They are, therefore, indifferent between buying the market and any other investment strategy. At the expected prices, good stocks will be 
oversubscribed. Bad stocks will be undersubscribed. Thus, only a proportion of the orders for good stocks will be filled at the initial low price; the remaining orders will be filled at the new price. As a result, good managers will make a profit. But, bad portfolio managers will be rationed and, anticipating this outcome, they will not participate when the price is equal to the unconditional expected value.

Finally, consider the case where initially posted prices are below the unconditional expected security values such that uninformed traders earn their opportunity cost. In order for liquidity traders to meet their need for cash, the uninformed must be induced to participate in the initial round of trading. This can only occur if the initially posted prices are below the unconditional expected security values thus demonstrating the proposition.

There are no uninformed traders other than liquidity traders in the Glosten and Milgrom model. Here there are bad portfolio managers who are uninformed. They, however, will not make money if they trade the asymmetric information stocks. Consequently, they will choose to trade the symmetric information stocks where they can make money. For these stocks there is no bid-ask spread. These are the potential bubble stocks which trade above their fundamental as discussed in Section 2. Note also that the good portfolio managers make money early on. If they were to trade in the symmetric information stocks they would effectively be trading with their own money since they would jeopardize losing their payment. Hence they are not prepared to trade in the market for symmetric information stocks and it is only the bad portfolio managers that participate.

\subsection{Optimal contracts for portfolio managers}

Good portfolio managers can benefit from their superior information during this initial round of trading. Ordinary investors can invest in these securitics on their own and obtain an expected return of $\delta$. Hence this is their opportunity cost. In order to be willing to lend to portfolio managers ordinary investors must obtain an expected return of at least $\delta$ from 
them.

Assumption (A16), concerning the absence of precommitment, is important because it ensures a pooling equilibrium. Investment firms make a loss einploying bad portfolio managers. Therefore, once they have identified a manager as bad, they will fire him. This implies that bad portfolio managers will behave in exactly the same way as good ones during the job application process no malter what contracts the firm offers; any contract which is attractive to good portfolio managers will also attract bad portfolio managers in the same proportions as they exist in the population. We start by considering this pooling equilibrium.

Since the investment firms earn zero profits and must earn a return equal to investors' opportunity cost of $\delta$ to attract lenders, it follows that the optimal payment schedule must satisfy the following program:

$$
\max _{\pi(y)} E_{g}[y-\pi(y)]
$$

subject to

$$
\gamma E_{g} \pi(y)+(1-\gamma) E_{\mathbf{s}} \pi(y) \geq B(1+\delta)
$$

where $E_{g}$ denotes the expectation operator with respect to the good portfolio managers' distribution of returns and $E_{s}$ denotes the expectation operator with respect to the distribution for the bad portfolio managers that speculate.

It is possible to show the following.

Proposition 3 When $\delta=0, \gamma=0.157, B=1, \alpha=0.95$, and the portfolio managers are risk neutral, the contract with the linear repayment schedule:

$$
\begin{aligned}
\pi^{*}(y) & =1+0.95(y-1) & & \text { for } y \geq 1 \\
& =y & & \text { for } y<1 .
\end{aligned}
$$

is such that lenders earn their opportunity cost and is an optimal contract.

It can readily be verified that investors earn their opportunity cost. To see this that the contract is optimal consider the first part of the schedule specified in (10). The good 
portfolio managers only produce outputs in this region. The expected revenue received from them is given by

$$
E_{g} \pi(y)=\int_{1}^{\frac{1}{3}} 2 \pi(y) d y+\int_{\frac{1}{3}}^{2}\left(\frac{1}{2}\right) \pi(y) d y .
$$

For $y \geq 1$ the expected revenue received from the bad portfolio managers is

$$
E_{,}^{1} \pi(y)=\frac{2}{3} E_{g} \pi(y)
$$

where the superscript 1 refers to the expectations taken over the range $y \geq 1$. Hence, no matter what the form of the payment schedule $\pi(y)$ the amount of revenue raised from the bad portfolio managers is always $2 / 3$ the amount raised from the good managers; altering the form of the payment schedule for $y \geq 1$ does not enable any more to be extracted from the bad group. It follows that the first part of the schedule in the proposition is optimal.

The second part of the schedule for $y<1$ is also optimal because only bad portfolio managers produce outputs which fall in this region. The good portfolio managers' utility is unaffected by the form of the payment schedule in this region and lowering the payment below $y$ can only reduce the revenue raised from the bad portfolio managers. Thus, the second part of the payment schedule is optimal.

Since $\delta=0$ the bad portfolio manager is clearly better off speculating than investing in all securities. The fact that $\delta=0$ also means it is not worthwhile changing the payment schedule so that the bad portfolio managers choose to invest in all securities since the expected rcturn on these is the same as investing in the bubble security. Hence, the proposition is demonstrated.

\subsection{Discussion}

The call option form of portfolio managers' compensation schemes creates the possibility of bubbles, as outlined in the analysis of Section 2. Bad portfolio managers will be willing to trade bubble securities at prices which are higher than the highest fundamental perceived 
by any of the traders. For example, suppose that one of the securities that is available is like that in Section 2 and it is known by all traders to have a payoff of zero with certainty. Thus all traders have the same information sel with regard to this security and this is common knowledge. As in Section 2, the security can trade at a positive price so that there is a bubble. Even if groups have different beliefs about the fundamental of a security it will still be possible to show that bad portfolio managers will be willing to trade the stock at a price above the maximum. The call option feature of portfolio managers' compensation schemes means they can be willing to purchase a slock if there is some prospect of a capital gain even though they know with certainty that its price will fall below its current level at some point in the future. This means it would even be possible to use a definition of bubble where the price must be above the highest possible payoff which is given positive probability by any investor and still obtain examples of a bubble.

In order to derive the proposition it was assumed that all agents are risk neutral. If agents are risk averse then the form of the optimal contract will not be the same as that in Proposition 3; risk sharing will become a factor. Nevertheless, the characteristics of the contract will usually be similar. Il will be optimal to extract revenue from the bad portfolio managers by penalizing poor performance and rewarding good performance. Although the optimal contract may not have the exact form of a call option, it may often provide incentives for bad managers to speculate and go for large risky payolfs even when this is associated with poor average returns.

Assumption (A16), about the absence of precommitment, ensured that only a pooling equilibrium existed. If investment firms can precommit to retain a manager even when they know he is bad and will not make profitable investments, then a pooling and a separating equilibrium may exist. The pooling equilibrium is the same as that described above. The separating equilibrium involves the investment firm offering a menu of contracts to separate the good managers from the bad. In a separating equilibrium, there are two payment sched- 
ules: one for the good managers, $\pi_{g}$, and one for the bad managers, $\pi_{b}$. These are chosen to maximize (8) subject to (9) and the constraints that the bad managers do not have a strict incentive to want to mimic the good managers and vice versa. Thus, the assumption of no precommitment plays an important role in the analysis since it ensures a pooling equilibrium.

In the setting of this section the bad managers always pooled with the good managers. It is worth pointing out an alternative assumption which would also result in bubbles. Suppose that portfolio managers do not learn whether they are good or bad until after their contracts have been signed. In this case there is no possibility of a separating equilibrium and if the contracts are designed to minimize losses due to the bad portfolio managers, the optimal contract can again be like a call option.

\section{Robustness and implications}

This essay has addressed a theoretical question, namely, can a security trade above its fundamental when there are a finite number of traders with a finite amount of wealth, and there is a finite horizon? We have shown that their exists a class of models different from those considered by Tirole (1982) where rational behavior is consistent with security price bubbles. The bubbles can grow at any rate, at least for short periods. If one imagines repetitions of the model, nothing rules out bubbles starting again after they have crashed in the previous period. They can occur on finitely lived securities. Clearly similar bubbles could occur with infinitely lived securities. Perhaps most importantly, the model explains the setting in which bubbles can arise and shows when and how they end.

We have demonstrated the existence of bubbles by considering a specific example. For tractability the assumptions made were very specific. This was necessary to enable a set of self-fulfilling beliefs that ensure existence of equilibrium to be identified. An important question concerns the robustness of this example. In other words how general is the class of models in which bubbles can arise? There are four elements of the example that appear 
crucial to the result:

1. At any point in time there must be an infinite number of trading possibilities before the horizon.

2. Agents must be unable to deduce whether or not they are the last person in the market.

3. Markets are inefficient so that there exists a group of portfolio managers that makes an above normal rate of return which allows the losses of the bad portfolio managers to be covered.

4. The agency relationship between investors and portfolio managers involves a compensation scheme for the managers which has the form of a call option and can induce risk loving behavior.

We discuss each of these points in turn and then make some final comments.

Continuous time is an important feature of our model because it allows for an infinite number of trading possibilities even though the horizon of the model is finite. This alone does not allow bubbles to exist. In our model there are a finite number of agents, and Tirole (1982) showed that bubbles cannot exist in infinite horizon models with a finite number of agents. While it is clear that bubbles of the type considered in this paper require an infinite number of trading possibilities, the example we presented is not isomorphic to an infinite horizon overlapping generations model; there are a finite number of agents in our model whereas in an overlapping generations model there is an infinite number of agents. Nevertheless, it is possible to reinterpret the model here as an infinite horizon model with infinitely-lived agents.

The second point concerns the information that agents have. The factor that is critical for our result is that agents have an identification problem. In particular, they must not be able to deduce whether or not they are the last person. In the example presented, adding one 
piece of information allows traders to determine whether they are the last person. However, this does not mean that the result is not robust since adding an extra source of noise restored the original result, as shown in Section 2.3 .

The third point relates to the assumption that securities markets are not strong-form efficient. There are a number of ways in which markets may not be strong-form efficient. We modelled this inefficiency by assuming the presence of some traders with urgent needs to trade, following Glosten and Milgrom (1985). All that is really required is some form of inefficiency where one group can outperform another. For example, a version of the Grossman and Stiglitz (1980) model where a group of traders has a comparative advantage at gathering information, will lead to similar results.

The fourth point concerns the importance of a compensation scheme for portfolio managers that has the form of a call option and induces risk loving behavior. In the examples above the bubbles can be thought of as a manifestation of the inefficiency resulting from this aspect of the agency relationship between investors and portfolio managers. This is the counterpart of the well-known result in the corporate finance literature that debt-financed firms may be willing to accept negative net present value investments (see, e.g., Jensen and Meckling (1976)).

An important assumption of the analysis showing this type of compensation scheme is optimal is that the minimum payoff to portfolio managers is zero. This implies that they cannot be penalized at all. As in many models of agency relationships, if the agent can post his own capital to guarantee performance, the agency problem is mitigated and may disappear. For example, in the corporate finance context if firms can post enough collateral to guarantee the loan they will not have an incentive to undertake negative net present value projects. This solution is not often feasible since firms often cannot post collateral. Similarly, in many situations portfolio managers will not be able to post capital to guarantee their performance. 
In practice, portfolio managers do not usually bond themselves in this way. Prior to 1985 in the U.S., for example, the SEC prohibited investment fees from depending directly on the change in value of the portfolio. Typically, the fees for portfolio managers were based on assets under management. Thus, if a manager did well then his fees would increase because new investors would be attracted to invest under his direction. There were no payments from the manager to the investors if performance was bad. The worst that could happen as a result of poor manager performance was a zero fee (see Grinold and Rudd (1987)). Since 1985 incentive fees have been permitted. Kritzman (1987) points out that in this case:

Incentive fees are typically structured with two components-a base fee, ... and a contingent fee, which allows the manager to share in the incremental return relative to an established benchmark. The manager does not usually share in negative relative returns; that is, he does not pay his client when he underperforms the benchmark. This asynumetric structure essentially grants the moncy manager a call option on some fraction of incremental return. ... It is possible that a manager ... will expose the portfolio to undue risk in the absence of any insights whatsoever. (p. 21, 22.)

Thus, our modelling of the compensation scheme for portfolio managers as a call option, which is essential to the results in the model, tends to correspond to what is observed in practice. Also its possible inducement of risk-loving behavior is well-recognized.

There are two further considerations with regard to the agency relationship. The first concerns the available alternative investments. In the example of Section 3 it was shown that it was strictly better for the bad portfolio managers to invest in the bubble security than the alternatives. In general, this result will not hold if the alternatives are sufficiently attractive. However, given the call option feature of the compensation scheme it will hold in many situations. The second consideration concerns the effects of repeating the relationship. Often in agency models the effects of reputation mitigate the problem. In portfolio management it is not clear this occurs. Bad managers must consistently produce high returns in order to remain pooled with good managers. In order to achicve this they have to take risky positions. Thus the problem may be exacerbated rather than mitigated. 
Any arguments concerning the generality of the example presented are clearly only speculative. The important issue for future research is to identify more precisely how general is the class of models where bubbles exist. Our approach is one of a number based on rational behavior that is currently being developed. Work related to ours includes that of Faust (1989). He demonstrates the existence of fiat money in a finite horizon model. In a continuous time setting, Faust shows that if the finite horizon is far enough away, then the terminal point does not rule out the existence of fiat money. 
We are grateful to Andy Abel, Sugato Bhattacharya, Colin Camerer, Joe Haubrich, Alan Kraus, Max Maksimovic, Steve 0'Connell, Gordon Sick, Chester Spatt, Mark Weinstein, Randy Wright, Josef Zechner, Steve Zeldes and participants at seminars at London School of Economics, Columbia University, Cornell University, Stanford University, University of British Columbia, University of North Carolina-Duke, the University of Pittsburgh, University of Pennsylvania, University of Rochester, the 1988 Johnson Symposium at the University of Wisconsin, and two anonymous referees for many helpful suggestions. This research began as joint work with Peter Knez to whom we remain indebted. The authors alone are responsible for errors and omissions. Financial support was provided to the first author by NSF grant nos. SES 8813719 and SES 8920048 and to the second author by NSF grant no. SES 8618130 . 


\section{References}

Allen, Franklin and Gary Gorton (1988), "Rational Finite Bubbles," University of Pennsylvania, Rodney L. White Working Paper \#41-88.

Blanchard, Olivier (1979), "Speculative Bubbles, Crashes and Rational Expectations," Economic Letters 3, 387-89.

Blanchard, Olivier, and Mark Watson (1982), "Bubbles, Rational Expectations, and Financial Markets," in P. Wachtel (ed.), Crises in the Economic and Financial Structure, (Lexington Books; Lexington, Mass.).

Camerer, Colin (1989), "Bubbles and Fads in Asset Prices: A Review of Theory and Evidence," Journal of Economic Surveys 3(1), p. 3-41.

DeLong, J. Bradford, Andrei Shleifer, Lawrence Summers, and Robert Waldmann (1990), "Noise Trader Risk in Financial Markets," Journal of Political Economy.

Diba, Behzad, and Herschel Grossman (1988), "Rational Inflationary Bubbles," Journal of Monetary Economics 21(1), 35-46.

Faust, Jon (1989), "Supernovas in Monetary Theory: Does the Ultimate Sunspot Rule Out Money," American Economic Review 79(4), 872-881.

Flavin, Marjorie (1983), "Excess Volatility in Financial Markets: A Reassessment of the Empirical Evidence," Journal of Political Economy 91, 929-56.

Flood, Robert, and Peler Garber (1980), "Market Fundamentals Versus Price-Level Bubbles: The First Tests," Journal of Political Economy 88, 745-70.

Garber, Peter (1989), "Tulipmania," Journal of Political Economy 97, 535-560. 
Glosten, Lawrence and Paul Milgrom (1985), "Bid, Ask and Transaction Prices in a Specialist Market With Heterogeneous Informed Traders," Journal of Financial Economics $14,71-100$.

Grinold, Richard, and Andrew Rudd (1987), "Incentive Fces: Who Wins? Who Loses?" Financial Analysts Journal (January-February), 27-38.

Grossman, Sanford, and Robert Shiller (1981), "The Determinants of the Variability of Stock Market Prices," American Economic Review 71, 222-27.

Grossman, Sanford, and Joseph Stiglitz (1980), "On the Impossibility of Informationally Efficient Markets," American Economic Review 70, 393-408.

Ilarrison, J. Michael, and David Kreps (1978), "Speculative Behavior in a Stock Market with Heterogeneous Expectations, ${ }^{n}$ Quarterly Journal of Economics 92, 323-36.

Hellwig, Martin, (1986), "Recent Developments in the Theory of Insurance," unpublished seminar notes.

Jensen, Michael, and William Meckling (1976), "Theory of the Firm: Managerial Behavior, Agency Costs and Ownership Structure," Journal of Financial Economics 3, 305-60.

Kileidon, Alan (1986a), "Bias in Small Sample Tests of Stock Price Rationality," Journal of Business 59, 237-61.

Kleidon, Alan (1986b), "Variance Bounds Tests and Stock Price Valuation Models," Journal of Political Economy 94, 953-1001.

Kritzman, Mark (1987), "Incentive Fees: Some Problems and Some Solutions," Financial Analysls Journal 43, 21-26. 
Leroy, Stephen, and Richard Porter (1981), "The Present Value Relation: Tests Based on Implied Variance Bounds," Econometrica 49, 555- 574.

Marsh, Terry, and Robert Merton (1986), "Dividend Variability and Variance Bounds Tests for Rationality of Stock Prices," American Economic Review 76, 483-98.

Samuelson, Paul (1958), "An Exact Consumption-Loan Model of Interesl with or without the Social Contrivance of Money,” Journal of political Economy 66, 467-482.

Shiller, Robert (1981), "Do Stock Prices Move Too Much to be Justified by Subsequent Changes in Dividends?" American Economic Review 71, 421-36.

Shiller, Robert (1984), "Stock Prices and Social Dynamics," Brookings Papers on Economic Activity 2, 457-98.

Smith, Vernon, Gerry Suchanek and Arlington Williams (1988), "Bubbles, Crashes, and Endogenous Expectations in Experimental Spot Asset Markets," Econometrica 56, 1119-1151.

Tirole, Jean (1982), "On the Possibility of Speculation Under Rational Expectations," Econometrica 50, 1163-81.

Tirole, Jean (1985), "Asset Bubbles and Overlapping Generations," Econometrica 53, 1499 1528.

Wallace, Neil (1980), "The Overlapping Generations Model of Fiat Money," in J. Karaken and N. Wallace (Eds.), Models of Monelary Economies, (Federal Reserve Bank of Minneapolis; Minneapolis).

West, Kenneth (1988), “Bubbles, Fads and Stock Price Volatility Tests: A Partial Evalua-

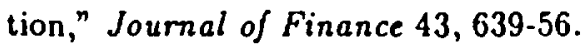


</ref_section> 


\section{FIGURE 1}

\section{Example with Unknown Deatlı Times}

TRUE VALUES OF DEATII TIMES: $t_{1}=0.1 ; t_{2}=0.4 ; t_{3}=0.7$.

\section{SEQUENCE OF EVENTS}

\begin{tabular}{|c|c|c|c|c|}
\hline$t=0$ & 0.1 & 0.1 & 0.6 & 0.7 \\
\hline $\begin{array}{l}\text { PERSON } 1 \\
\text { endowed } \\
\text { with share }\end{array}$ & $\begin{array}{l}\text { PERSON } 1 \\
\text { finds out he's } \\
\text { going to die. } \\
\text { He searches } \\
\text { lor a buyer. } \\
\text { Suppose he } \\
\text { finds PERSON } \\
2 \text { who buys. }\end{array}$ & $\begin{array}{l}\text { PERSON } 2 \\
\text { searclies for a } \\
\text { buyer and finds } \\
\text { PERSON } 3 \\
\text { who buys. } \\
\text { PERSON } 2 \\
\text { dies. }\end{array}$ & $\begin{array}{l}\text { PERSON } 3 \\
\text { searches for } \\
\text { a buyer. } \\
\text { None is } \\
\text { found. The } \\
\text { bubble bursts. }\end{array}$ & $\begin{array}{l}\text { PERSON } 3 \\
\text { dies. }\end{array}$ \\
\hline
\end{tabular}




\section{FIGURE ?}

The Buyer's Conjectures about the Seller's Identity

\begin{tabular}{|c|c|c|c|c|c|}
\hline$t=0$ & 0.1 & 0.4 & 0.6 & 0.7 & \\
\hline $\begin{array}{l}\text { ACTUAL } \\
\text { IDENTITIES }\end{array}$ & $\begin{array}{l}\text { BUYER } 2 \\
\text { SELLER } 1\end{array}$ & $\begin{array}{l}\text { BUYER 3 } \\
\text { SELLER } 2\end{array}$ & \multicolumn{2}{|c|}{$\begin{array}{l}\text { BUYER NONE } \\
\text { SELLER } 3\end{array}$} & \\
\hline $\begin{array}{l}\text { BUYER'S } \\
\text { CONJECTURES }\end{array}$ & $\begin{array}{l}\text { SELLER MUST } \\
\text { BF I SINCE } \\
t<0.33, t_{1}=0.1 \\
\text { and } t_{2}=0.4 \text {. } \\
1 \text { should sell at } \\
0.4 \text {. My gross } \\
\text { profils }=0.4- \\
0.1=0.3 . \text { My } \\
\text { payoft is } 2 \% \\
\text { of this }(>0) \text {. }\end{array}$ & $\begin{array}{l}\text { SELLER C } \\
\text { BE 1, 2, O } \\
\text { SELLER } \\
t_{2}=0.6 . \\
\text { my groas } \\
0.6-0.4 \\
\text { payoff is } \\
\text { this (>0) } \\
\text { SELLER } \\
\text { PERSON } \\
t_{1}=0.1 . \\
\text { able to re } \\
\text { payoff }= \\
\text { Payoff }= \\
\text { SELLER } \\
\text { PERSON } \\
t_{1}=0.1 . \\
\text { figured on } \\
\text { as when s }\end{array}$ & $\begin{array}{l}\text { ILD } \\
\text { 1 THEN } \\
\text { sell then } \\
\text { fits = } \\
\text {.2. My } \\
\text { of } \\
2 \text { THEN } \\
\text { sold at } \\
\text { on't be } \\
\text { Gross } \\
\text { 4. My } \\
\text { 3 THEN } \\
\text { sold at } \\
\text { RSON } 3 \\
\text { 2. Payofts } \\
\text { or is } 2 \text {. }\end{array}$ & $\begin{array}{l}\text { PROBABILITY } \\
\qquad .4\end{array}$ & $\begin{array}{l}\text { Expected } \\
\text { payoft from } \\
\text { buying }>0\end{array}$ \\
\hline
\end{tabular}


FIGURE 3

Distribution of Unknown Death Times

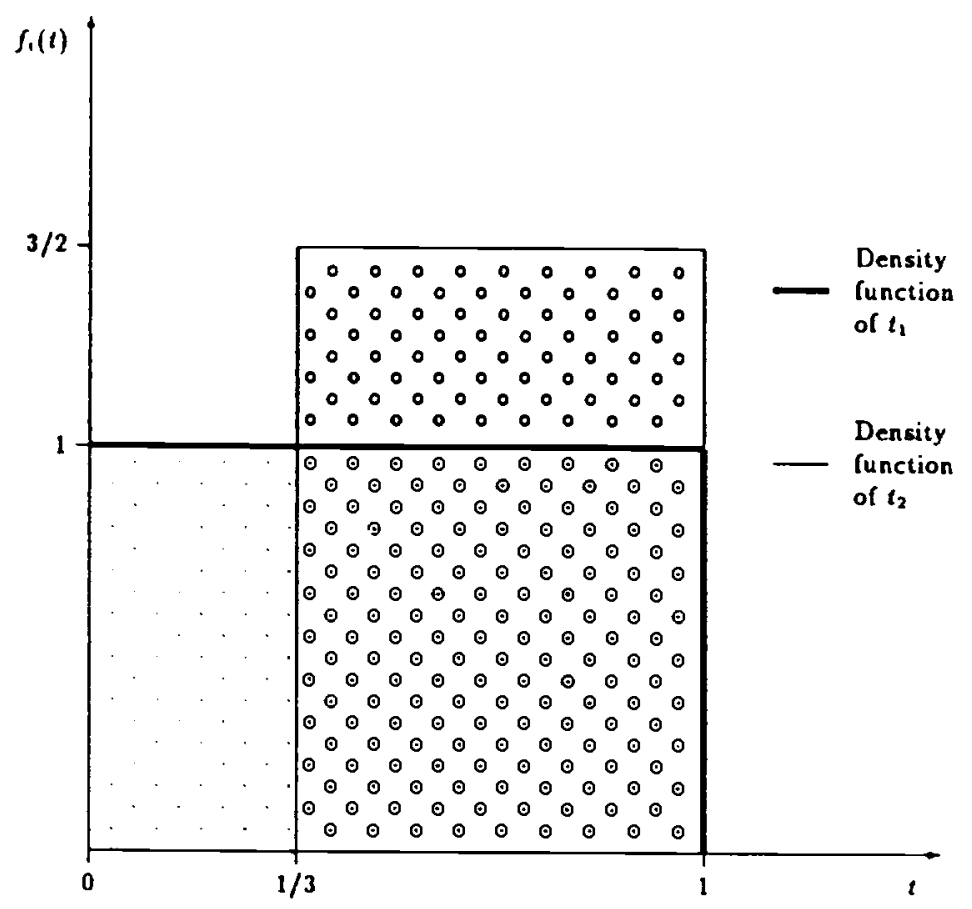




\section{FIGURE 4}

The Entire Stock Market

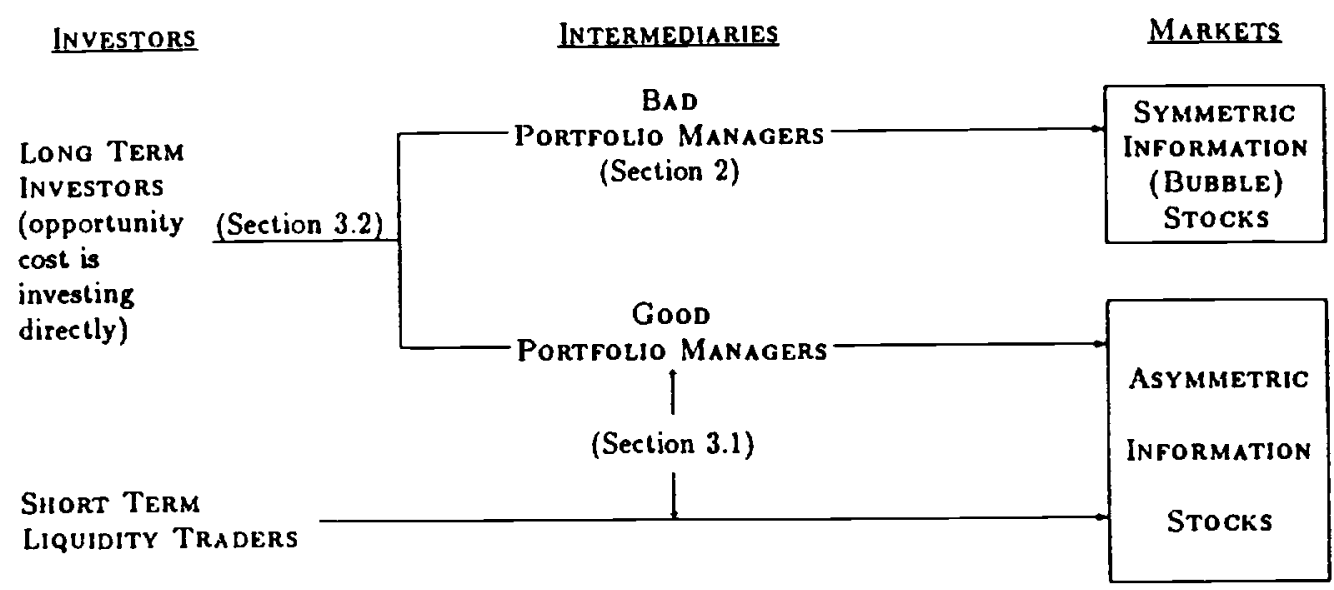




\section{FIGURE 5}

Probability Distributions of Returns by Agent Type

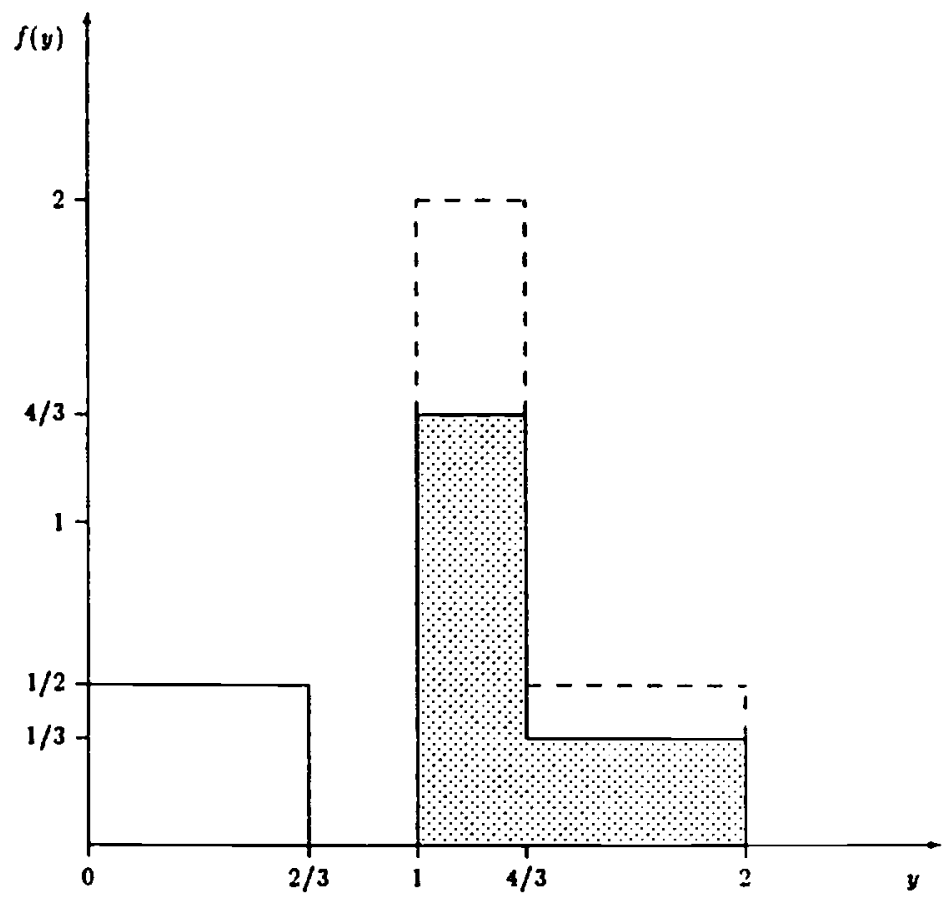

